\title{
ENERGY LOSSES IN SOME CONDENSERS USED IN HIGH-FREQUENCY CIRCUITS
}

\author{
By L. W. Austin
}

The following experiments have been carried out for the purpose of determining the energy losses in different types of sending condensers, including compressed air, Leyden jars in air and immersed in oil, paper condensers, and molded condensers (composition dielectric), all used, with the exception of a few experiments, at a maximum voltage of 14500 volts, this being a voltage which is frequently employed in the newer wireless sets of the United States Navy. In most of the tests the condensers were of approximately
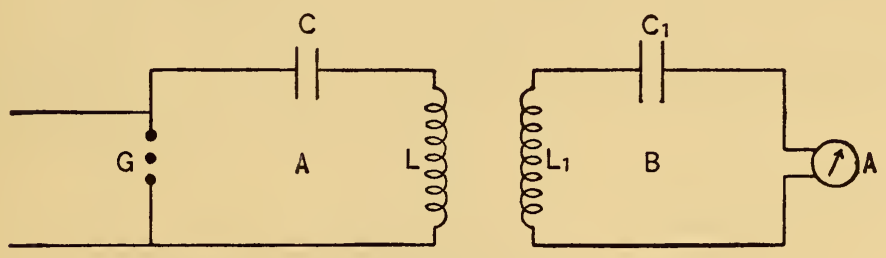

Fig. 1

0.006 microfarad capacity and the wave length was about rooo meters. Current was taken from the city mains at 60 cycles and raised to the necessary voltage by means of an open-core transformer.

Two forms of circuit were used in the experiments. The first form, in which an absolute determination of the losses of the compressed-air condenser was made, is shown in Fig. I. In this circuit A contains a quenched gap $\mathrm{G}$ of the Telefunken type, a condenser consisting of seven Leyden jars in air, and an inductance sufficient to produce a wave length of rooo meters. To this was coupled the testing circuit proper $B$, which was made up of the 
condenser under test, an inductance, and a hot-wire ammeter. The inductance was of the flat strip Fessenden type and consisted of a coil of 30 turns, $19 \mathrm{~cm}$ in diameter and $8 \mathrm{~cm}$ in length, of which about 12 turns were used. The phosphor-bronze strip of which the coil was composed was $0.62 \mathrm{~cm}$ wide and $0.13 \mathrm{~cm}$ thick, the wide dimension being perpendicular to the axis of the coil. This method of winding gives great compactness with large currentcarrying capacity, but has the disadvantage of placing a considerable amount of metal at right angles to the lines of magnetic force, thus tending to produce eddy currents. The hot-wire ammeter was of the 6-ampere General Electric type and was provided in most cases with a shunt, the shunt ratio being determined for the frequency used. The high-frequency resistances

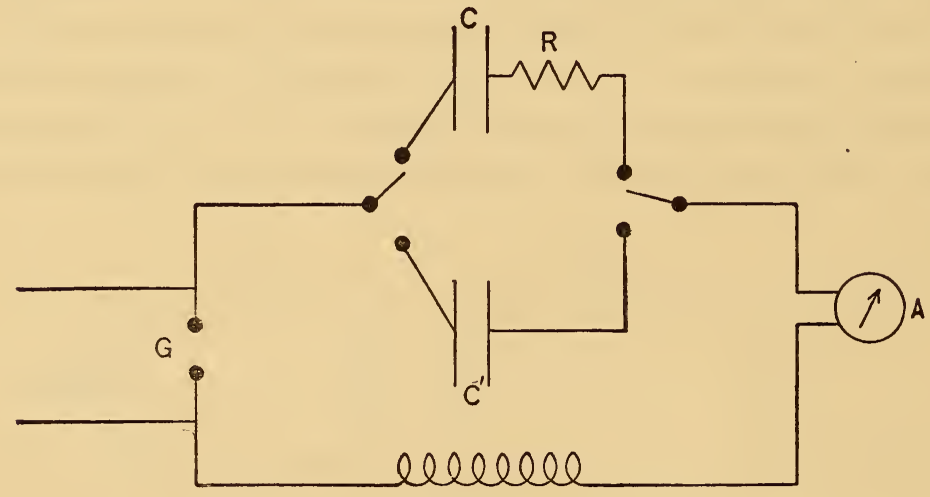

Fig. 2

were of manganin wire $0.08 \mathrm{I} \mathrm{cm}$ in diameter inserted in mercury cups. These wires had the same direct current and high-frequency resistance at the frequencies used, as was determined by special experiments. Wave length and decrement measurements were made in the usual way by means of a wave meter with thermoelement and galvanometer.

The second form of circuit is shown in Fig. 2 and is identical with the first form except that the quenched gap circuit is omitted and a parallel cylinder spark gap is introduced into the testing circuit. The spark gap consisted of two parallel cylinders of zinc adjustable for distance and parallelism. In this form of gap the spark runs from point to point insuring good insulation after each 
discharge without the use of a blower when a moderate amount of power is used. The spark voltage was determined by a parallel micrometer gap.

The Leyden jars furnished for the test were all of them of the copper-coated type. Two types were furnished by the Wireless Specialty Co., type I having a somewhat heavier copper coating than type 2. The Moscicki condensers were of their well-known form incased in brass tubes with the glass thickened at the edges of the conducting coatings and with these edges covered by an insulating liquid. The paper condenser was of a well-known make.

\section{LOSSES IN THE COMPRESSED-AIR CONDENSER}

The apparatus in this experiment was arranged as shown in Fig. I, the object being the absolute determination of the resistance of the standard compressed-air condenser already described. The data of the experiment are given in Table I. According to this the resistance of the condenser is $0.14 \mathrm{ohm} .{ }^{1}$ It is not certain that this is all a resistance in the condenser proper, but it may consist partly of contact resistance and may be also in part due to eddy current losses, owing to the proximity of the large metal case of the condenser to the rest of the circuit. The amount may quite possibly be in error by $0.05 \mathrm{ohm}$.

\section{TABLE I}

\section{Resistance of Compressed-Air Condenser}

[Quenched gap excitation. See Fig. r]

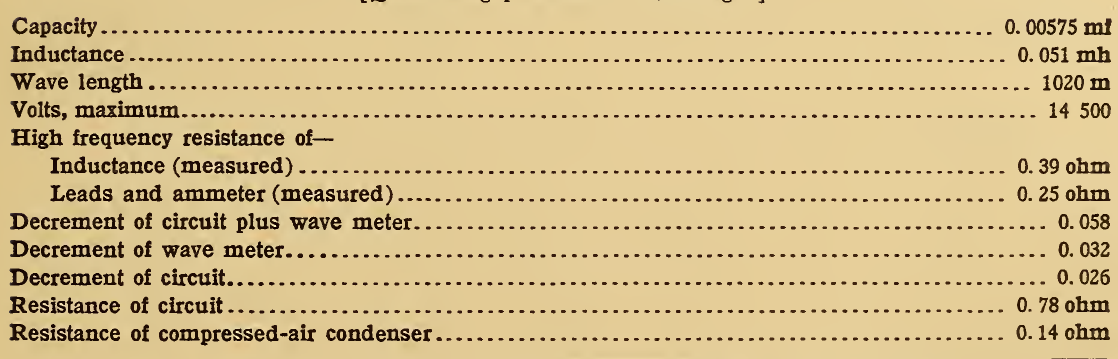

1 In some other experiments with a different arrangement of apparatus a loss equivalent to as much as $0.25 \mathrm{ohm}$ was observed in the air condenser. 


\section{COMPARISON OF CONDENSERS AT CONSTANT VOLTAGE}

The arrangement of the apparatus is shown in Fig. 2. The equivalent resistance of the condensers was determined as follows: The current in the main circuit was first measured with a Fessenden compressed-air condenser of 0.00575 microfarad capacity. This being taken as a standard, the current was next determined, using the condensers to be tested, the capacity always being approximately the same as the compressed air. The switch was then shifted so as to throw the compressed-air condenser again into circuit and sufficient manganin resistance wire placed in circuit to reduce the current to the same value as that observed with the condenser being tested, this resistance representing the difference between the compressed air and the condenser under test. In order to take account of the slight variations in current, observations of the ammeter were made every 5 seconds for 50 seconds and the average taken. To give an idea of the degree of steadiness of the current and the accuracy of the observations, the record of one complete set is given in Table II. It was found necessary at the close of each set of readings to clean the gap, as otherwise the readings became less regular and in general the resistance of the gap increased.

\section{TABLE II}

Ammeter Readings for Three Wireless Specialty Jars in Air, and Compressed-Air Condenser

[ 14500 volts. Wave length $1000 \mathrm{~m}$. Current about 8 amperes]

\begin{tabular}{l|l|l|l}
\hline W. S. (1) & C. A. +0.9 ohm & W. S. (1) & C. A.+0.8 ohm \\
\cline { 1 - 2 } 44 & 44 & 44 & 45 \\
43.5 & 44.5 & 44 & 45 \\
44 & 43 & 44 & 44.5 \\
44 & 43.5 & 44.5 & 44.5 \\
44.5 & 43.0 & 44 & 44 \\
44 & 43.5 & 44.5 & 45 \\
44 & 43 & 43.5 & 44.5 \\
44 & 43.5 & 44 & 45 \\
44 & 43.5 & 44 & 45 \\
43.5 & 44 & 44.5 & 45 \\
\hline 43.95 & 43.55 & 44.10 & 44.75 \\
\hline
\end{tabular}

Difference in resistance $=0.86$ ohms. 
TABLE III

Condenser Resistances at Constant Voltage

[Volts $=14500(\max$.$) Current =7-8 \mathrm{amp}$. Wave-length $=1000 \mathrm{~m}$ (about)]

\begin{tabular}{|c|c|c|c|}
\hline 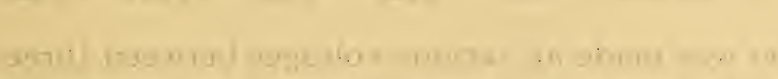 & Units & $\begin{array}{c}\text { Capacity } \\
\text { (mf) }\end{array}$ & $\begin{array}{l}\text { Resist- } \\
\text { ance } \\
\text { (ohms) }\end{array}$ \\
\hline \multicolumn{4}{|l|}{ Leyden jars in air: } \\
\hline 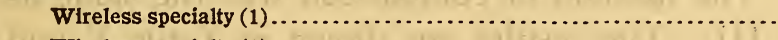 & 3 & 0.00603 & 1.08 \\
\hline Wireless specialty (2)......... & 3 & .00605 & 1.19 \\
\hline 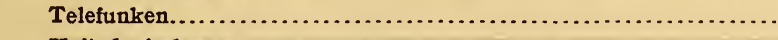 & 3 & .00612 & 1.59 \\
\hline 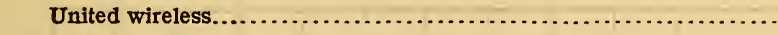 & 2 & .00603 & 1.83 \\
\hline 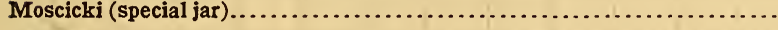 & 1 & .00548 & 0.57 \\
\hline Paper................................................... & 1 & .00580 & 2.19 \\
\hline Murdock (molded condensers) ............... & 3 & .00535 & 0.41 \\
\hline Molded micanite ................................... & 3 & .0041 & 2.91 \\
\hline 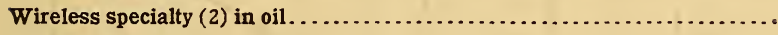 & 3 & .00605 & 0.28 \\
\hline Glass plates in oil.................................. & 2 & .0042 & 0.58 \\
\hline 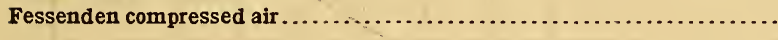 & 1 & .00575 & 0.14 \\
\hline
\end{tabular}

Table III contains the comparison of various condensers with the Fessenden compressed-air condenser at i 4500 volts.

In order to determine the actual resistance of the condensers as given in the table it was necessary to add to the resistance difference observed the resistance of the compressed-air condenser and a small correction for the differences in current due to slight differences in capacity. A curve for this purpose was determined experimentally. In the case of the paper, the molded condenser, and the jars and plates in oil, brushing was for the most part prevented by their construction. Their losses, therefore, are in the dielectric. The rather high energy loss of the jars in air is chiefly a brush loss.

\section{COMPARISON OF CONDENSERS AT VARIOUS VOLTAGES}

The decrement of the circuit containing the three wireless specialty jars in oil was measured at voltages from 4700 to I8 500 volts, the apparatus being arranged as in Fig. $\mathbf{I}$. The results are given in Table IV. It is seen that there is no certain change in the decrement between these limits of voltage. Similar experiments were also carried on with glass plates in oil, the compressedair condenser, and with the Murdock molded condensers with the same result. 
TABLE IV

Leyden Jars in Oil at Various Voltages

Volts (maximum) 4700

$\begin{array}{rr}7100 & 11400 \\ 0.0440 & 0.0445\end{array}$

Next a comparison was made at various voltages between three jars in oil and three jars in air of equal capacity, the circuits of Fig. I being used. The method of comparison was the same as that used in Table III. The results are shown in Table V and

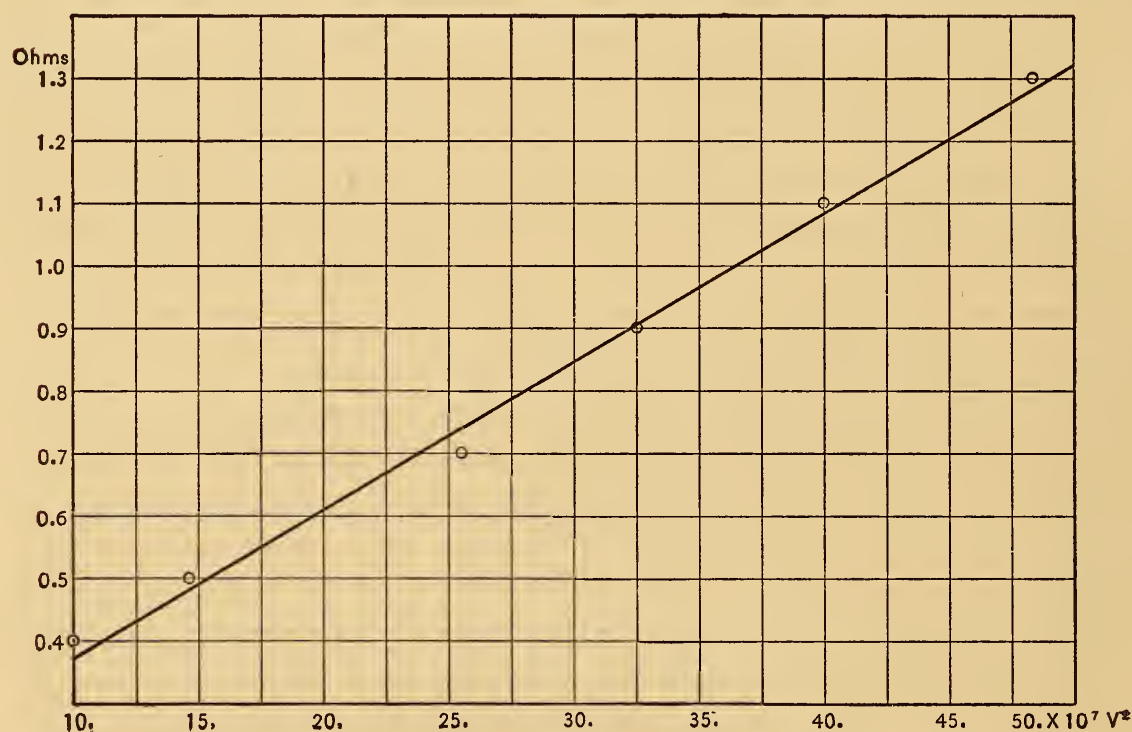

Fig. 3

Fig. 3. The table and figure indicate that the losses of the jars in air increase approximately as the square of the voltage ${ }^{2}$ from Io 000 volts where the brushing becomes noticeable up to about 22000 volts. Above this point the increase becomes more rapid. It was observed that the glass at the edges of the conducting coatings became very hot above this voltage and it seems probable that here the internal losses begin to increase rapidly. 
TABLE V

Leyden Jars in Air at Various Voltages

\begin{tabular}{c|c|c}
\hline Volts (maximum) V & $\mathbf{V}^{2}$ & Resistance (ohms) \\
\hline $10 \times 10^{3}$ & $10 \times 10^{7}$ & 0.4 \\
12 & 14.4 & 0.5 \\
16 & 25.6 & 0.7 \\
18 & 32.4 & 0.9 \\
20 & 40.0 & 1.1 \\
22 & 48.4 & 1.3 \\
\hline
\end{tabular}

From Table $\mathrm{V}$ a conclusion may be drawn which is contrary to the ordinarily accepted view; that is, that up to about 20000 volts the brushing losses are not reduced by placing jars in series if the capacity and voltage remain the same. For if one jar be replaced by four jars in parallel series, the voltage on each jar is reduced to one-half and the loss per jar to one-fourth. The brushing surface is increased four times, therefore the total loss remains the same. An experiment carried out at about 15000 volts proved that this conclusion was correct.

Another fact which was observed in connection with these experiments is not so easily explained. It was found that the losses in Leyden jars with only their edges immersed in oil are considerably greater than when the whole conducting surface is covered. This result is opposed to the idea that the air losses lie wholly at the edges of the conducting coatings. Observations were also made during the test on losses in jars which had remained for a long time in oil under constant use and also on jars which had been placed in oil and were afterwards used in air without a thorough cleaning. In the first case it was found that when heavy oils were used there was a certain tendency toward carbonization at the edges of the conducting coatings, producing a slight increase in resistance with time. This effect was much more marked when the oil-covered jars were afterwards used in air. When these jars with the carbonized oil at the edges of the plates were replaced in oil the losses continued, often amounting to an equivalent resistance greater than that of clean jars in air. This shows the necessity of keeping the glass around the edges of the conducting plates 
of condensers thoroughly clean. ${ }^{3}$ When condensers are immersed in oil this should be of a noncarbonizing variety.

\section{SUMMARY}

Under the conditions of these experiments the following results were obtained:

I. The losses in the compressed air condenser used amount, at a pressure of 15 atmospheres, to an equivalent resistance of between 0.1 and 0.2 ohms.

2. Condensers in which brushing is prevented by the nature of their construction show no change in resistance between the limits of observation, 4000 to 20000 volts, indicating that the internal losses are independent of voltage.

3. Leyden jars of commercial types immersed wholly in oil show losses but slightly greater than those of the compressed-air condenser.

4. The paper and micanite condensers measured show very much larger losses.

5. The resistances of the different Leyden jars in air vary between $I$ and I. 8 ohims at 14500 volts. Between 10 ooo and 20000 volts the equivalent resistance increases approximately in proportion to the square of the voltage.

6. Placing Leyden jars in parallel series, the capacity remaining the same, does not diminish their brushing losses below 20000 volts.

7. Immersing only the edges of the conducting coatings of Leyden jars in oil gives an equivalent resistance midway between that observed when wholly in air or wholly in oil.

8. Brushing losses are much increased by any semiconducting material on the surface of the glass at the edges of the conducting coatings of Leyden jars.

I wish to express my obligations to my assistants, Minerratti and Evans, chief electricians of the United States Navy.

U. S. NAVAL, RADIOTELEGRAPHIC LABORATORY,

WASHINGTON, March I, I9I2.

${ }^{3}$ The great difference in brushing losses observed in different specimens of glasses is perhaps due to the differences in their hygroscopic character. 